\title{
Lobato e o pequeno leitor do século XXI
}

\section{Lobato and the small 21st century reader}

https://doi.org/10.34112/2317-0972a2020v38n78p67-78

\section{Adriana Pastorello Buim Arena ${ }^{1}$}

RESUMO: Professores relutam em recomendar para o ensino fundamental dos anos iniciais a leitura de contos de alta qualidade como, por exemplo, Conto de escola, de Machado de Assis. Poder-se-ia levantar a hipótese de que relutam porque Machado de Assis escreveu para o público adulto. Entretanto, a obra de Monteiro Lobato também não tem sido frequentemente recomendada e a mesma hipótese não poderia ser aceita, porque ele escreveu para crianças. A linguagem de meados do século XX parece já não encontrar ressonância nos jovens leitores do século XXI. Com o auxílio de artigos acadêmicos que discorrem sobre a natureza da linguagem e com a análise do capítulo um da obra Caçadas de Pedrinho, de Monteiro Lobato, pretende-se discutir, neste ensaio, como o processo de transformação da linguagem e os valores sociais afetam o status de uma obra em diferentes contextos históricos, sociais e culturais.

Palavras-chave: Linguagem; Caçadas de Pedrinho; Monteiro Lobato; jovem leitor.

ABSTRACT: Teachers are reluctant to recommend for early elementary school to read high quality short stories such as Machado de Assis' school tale. It could be hypothesized that they are reluctant because Machado de Assis had written to the adult public. However, Monteiro Lobato's work has not often been recommended either and the same hypothesis could not be

1. Universidade Federal de Uberlândia, Uberlândia, Minas Gerais, Brasil. 
accepted because he wrote for children. Mid-twentieth-century language no longer seems to resonate with young readers of the twenty-first century. With the help of scholarly articles that discuss the nature of language and the analysis of chapter one of the book Pedrinho's Hunts by Monteiro Lobato, we intend to discuss in this essay how the process of language transformation and social values affect the status of a work in different historical, social and cultural contexts. Keywords: Language; Caçadas de Pedrinho; Monteiro Lobato; young reader.

\section{INTRODUÇÃO}

As histórias de Monteiro Lobato para crianças são muito conhecidas, mas ao que parece, apenas de uma maneira imprecisa ou superficial, pelo menos no caso do ensino fundamental. São confundidas com episódios televisivos da antiga série Sítio do Picapau-Amarelo e sequer sabem as crianças que estas histórias foram escritas num tempo e num espaço, por um determinado autor.

Nesta perspectiva, parece-me preciso favorecer às crianças a leitura das obras de Lobato, selecionadas entre outras tantas, para que elas possam conhecer os textos de patrimônio literário (MARZLOFF, 2009). Por essa expressão, Marzloff aponta para aqueles textos que podem ser considerados inauguradores de uma nova ordem, seja ela de criação da literatura para crianças - o caso do Brasil com Monteiro Lobato seja de uma forma de escrever peculiar ao autor. Os textos de patrimônio não morrem porque são eles plenos de discursividade, possibilitam muitos outros discursos para além daquele que foi registrado no meio impresso ou digital. Propor a leitura das obras de Lobato é propor a leitura de textos de patrimônio. As crianças reconhecerão neles a herança cultural que carregam, e talvez poderão, na vida adulta, reler estas mesmas obras e perceber que nelas há questões sempre atuais, pois são obras permeáveis que atravessam o tempo. Incluir textos da literatura do passado, não tão distante assim, e textos atuais na vida escolar, integra a criança no processo sócio-histórico-cultural de constituição permanente de uma comunidade da cultura literária.

Levanto a hipótese de que a ausência de livros de Lobato nas escolas de ensino fundamental não esteja apenas relacionada à polêmica do racismo já tanto discutida, mas também à permanente transformação da linguagem e dos modos de as pessoas interagirem com e no mundo. Partindo dessa tese, a discussão, ainda que concisa devido ao espaço concedido a este artigo, apresentará uma forma de ver a linguagem em transformação a partir da obra Caçadas de Pedrinho, especificamente o capítulo um, E era onça mesmo! 
A linguagem, a cultura e os pequenos leitores

Estamos habituados a ouvir a palavra patrimônio e conhecemos bem seu sentido no que diz respeito ao conjunto de bens materiais que a família possui, mas quando esta palavra vem acompanhada dos adjetivos literário e cultural, já não estamos mais seguros de seu significado. Trago essa discussão porque entendo que o conceito ainda é bastante tímido na comunidade acadêmica brasileira, no que se refere à literatura infantil. Somente em 2014, quando estive na França para estudos, tomei ciência deste relevante conceito, isto é, o texto de patrimônio literário e cultural da literatura infantil. Não há um entendimento definitivo sobre a noção de texto de patrimônio, porque essa discussão ainda está em curso. Expandir esse debate é lutar para que a literatura infantil - antiga ou contemporânea - ganhe o reconhecimento pleno de seu valor e, consequentemente, de sua legitimidade. Logo, tomarei, como definição temporária do referido conceito, o livro de literatura infantil como espaço para transmissão de uma herança literária, histórica e cultural para as novas gerações. Como patrimônio, é indispensável sua presença na escola, local onde as crianças se apropriam dos saberes histórico-culturais criados e organizados pela humanidade. Parafraseando a expressão francesa, é preciso mettre en valeur o texto de patrimônio, colocá-lo na vitrine para que todos o vejam.

Desde que a literatura infantil começou a ser produzida, muitas mutações ocorreram, quer na forma de apresentação gráfica, quer no estilo do gênero. Ao que parece, têm sido as bibliotecas as instituições que mais se preocupam com o armazenamento do texto de patrimônio, porque o entendem como um objeto que porta cultura, mas elas não têm a mesma preocupação com sua exposição e divulgação. Quanto mais as instituições, os professores e os familiares ampliarem sua compreensão quanto à importância do texto de patrimônio, mais este estará nas bibliotecas, nas aulas e no seio familiar; debates em torno das temáticas que portam manterão vivas as culturas das gerações anteriores, pilares da nossa.

As crianças não são mais manipuláveis ou ingênuas do que muitos leitores adultos; elas também conseguem entrar no mundo da leitura simbólica. Elas podem ser leitoras entediadas, descuidadas, mas também perspicazes. Tudo isso dependerá muito da qualidade da mediação que o adulto proporciona a ela. Não se pode circunscrever a aprendizagem apenas ilhada dentro da própria cultura contemporânea, pois isso seria um processo de alienação e não de emancipação humana. 
Além disso, ler literatura infantil é uma prática que dura muito pouco. Quanto mais for extenso o élan provocado pela leitura, tanto mais será possível ser reativado o desejo de voltar a ler as mesmas obras quando nos tornarmos adultos, pais e avós. Essa é uma possibilidade de se passar a herança cultural; ela é passada como herança por quem a tem.

Alguns livros se tornam best-sellers quando são adotados por anos seguidos pela escola; outros são editados porque pais buscam por eles nas livrarias. Se a herança patrimonial material passa de pai para filho, também é passada a herança cultural. Ler um texto de patrimônio é alimentar a memória de sua própria história. Seria a família quem busca a leitura das obras de Lobato, ou a escola? Temos aqui uma pergunta a ser investigada, que por hora deixarei para outra oportunidade.

A linguagem é parte de uma cultura e disso decorre toda sua heterogeneidade, mas, ao mesmo tempo,

[...] é também constitutiva da cultura no sentido de ser ela o principal elemento semiótico que dá liga às inúmeras relações sociais e dá forma sígnica aos inúmeros processos imaginário-discursivos pelos quais os seres humanos, organizados socialmente, atribuem os mais diversos sentidos às suas condições existenciais e às suas experiências (FARACO, 2019, p. 52).

Para o autor, as linguagens - verbais e não-verbais - expressam culturas. $\mathrm{O}$ homem não vive apenas no meio físico natural, numa biosfera, mas também numa grande semiosfera, ou seja, um universo de signos. Aquilo que é produzido por uma sociedade carrega impresso nos objetos criados a ideologia da época. Artefatos antigos nos possibilitam entender a forma de viver e de pensar de uma dada sociedade que não existe mais. Do mesmo modo seria com a linguagem escrita; se ela se perde, perde-se com ela toda a cultura produzida na época, e na verdade se perde a capacidade de entender o que daquela cultura tem de constitutivo para a nossa atual.

Não pretendo aqui tratar do conceito cultura, pois isso mereceria um artigo completo, mas demonstrar indícios de que não há apenas uma cultura, mas variadas culturas que são forjadas no contexto de uma sociedade plural, heterogênea, contraditória e em constante devir no confronto com os embates da biosfera e da semiosfera, dois polos inseparáveis da cultura produzida pela humanidade.

Um trecho de Caçadas de Pedrinho pode ilustrar essa discussão: 
- É hora! Avança, macacada! - gritou Pedrinho, escorregando pela árvore abaixo.

Todos o imitaram. Apanharam as armas e se arrojaram contra a fera com verdadeira fúria. Narizinho esfregou-lhe a faca no lombo, como se a onça fosse pão e ela quisesse tirar uma fatia. O Visconde conseguiu, depois de várias tentativas, enterrar-lhe no peito o seu sabre de arco de barril. Emília fez o mesmo com o espeto de assar frango. Pedrinho macetou-lhe o crânio com a coronha da sua espingarda. Até Rabicó perdeu o medo e, depois de carregar de novo o canhão, deu-lhe um bom tiro à queima-roupa. Assim atacada de todos os lados, a onça não teve remédio senão morrer. Estrebuchou e foi morrendo. Quando deu seu último suspiro, Pedrinho, no maior entusiasmo de sua vida, entoou um canto de guerra:

- Ale guá, guá, guá...

- E todos responderam em coro:

- Hurra! Hurra! Picapau Amarelo!...

(LOBATO, 2019, p. 13).

Uma onça foi vista por Rabicó, que contou o fato para Pedrinho, que organizou uma caçada! Um evento comum para a época de Lobato (1882-1948). Uma onça causava danos se estivesse próxima de sítios e de fazendas, era tida como animal perigoso que matava gente e bicho de criação e por isso precisava morrer. Essa forma de pensar localizada num espaço-tempo de uma cultura específica, o Brasil entre as décadas de 20 a 60 - situada numa biosfera e numa semiosfera, permitia a caça, não apenas de onças, mas de tantos outros animais hoje extintos ou em extinção. Em 2019, os acordos sociais entre a biosfera e a semiosfera, ainda que fragmentados e contraditórios, caminham para o lado oposto, o da preservação de animais. Quando o jornal televisivo ou as mídias digitais anunciam que uma oncinha foi encontrada passeando ao lado da mãe, todos gostam e vibram pela nova vida. O retorno da onça!

No entanto, a turminha de Pedrinho é sanguinária para nossa cultura atual. Eles planejaram e se prepararam com armas letais para dar cabo da onça com satisfação; tirar sua vida é uma aventura realizada com sucesso, um prêmio para todos eles. Pedrinho, no maior entusiasmo de sua vida, entoou um canto de guerra. Os pequenos leitores da metade do século $\mathrm{XX}$, ao lerem esta história, não veem nenhum mal em tirar a vida da onça, porque a sociedade não via essa ação como um mal, ao contrário, os pais destas crianças poderiam também estar habituados com a caça e levar seus filhos nessa aventura. A caça era uma atividade cultural. 
A cultura e a história estão encarnadas no homem. Podemos falar de um homem-histórico-cultural com hífen, porque estes elementos não se separam; ao se tirar um deles se descaracteriza o conceito. Se no Brasil Lobato se inspirou no prosaico, no cotidiano de homens rurais que viviam a situação de caça, Perrault se inspirou na ameaça que era para os homens um lobo entre os séculos XVI e XVII. Segundo Moriceau (2014, p. 32),

É nessa época do reinado de Luís XIV que o lobo ganha sob a pena de homens de letras como Perrault ou La Fontaine uma dimensão trágica. De fato, se, nas Fábulas e Contos, o Canis lupus está tão presente, é porque representa uma ameaça que é adicionada às pragas que então conhecem os países. (Tradução minha).

O conto Chapeuzinho vermelho - que dispensa apresentações, justamente por ser um texto de patrimônio francês que por sua permeabilidade atravessou gerações do mundo inteiro - é o arquétipo das vítimas de lobos na época em que viveu Perrault. Como fugir da história? Lobo mata gente, onça pintada também! Se houver um retorno de onças em grande quantidade, voltaríamos a matar onças como troféus, como fez a turminha do sítio? E aí não seria mais problema ler Lobato, que relata cenas de violência para crianças? Como escolher uma obra violenta e fora do tempo, já que hoje nossos valores são outros?

Como já dito, o homem e o mundo estão em constante transformação, os eventos estão de certa forma relacionados, mesmo que não tenhamos clareza desse fato. A caça predatória de ontem gerou impactos ambientais hoje. A cultura construída e aceita pelos homens numa determinada biosfera favorável à caça criou também um semiosfera em que expressões como as usadas por Lobato - verdadeira fúria, esfregou-lhe a faca no lombo, enterrar-lhe no peito o seu sabre de arco de barril, macetou-lhe o crânio com a coronha da sua espingarda, um bom tiro à queima-roupa - eram admitidas como absolutamente normais, sem que houvesse nenhum tom antiético ou politicamente incorreto. Segundo Marzloff (2013, p. 313-314),

A capacidade de se descentrar, que permite adotar o ponto de vista dos outros, é a base da construção de valores universalistas. A escola utiliza literatura destinada aos jovens, porque ela apresenta numerosas situações que permitem a descentralização do leitor, capaz de se interessar pelo ponto de vista dos outros, mas também porque permite um experiência democrática que é a reflexão coletiva. A interpretação permite 
abstrair valores universais e a argumentação possibilita a descentralização. O debate interpretativo é o dispositivo escolar que permite confrontar interpretações divergentes de um mesmo texto. Os valores colocados em jogo nas obras literárias e as difíceis escolhas que presidem as condutas humanas permitem ao leitor exercer seu julgamento e entender os conflitos de valores e as contradições que se observam a todos. Tal dispositivo de reflexão coletiva é uma forma prática de emancipação por meio da ação. (Tradução minha).

Os alunos desenvolverão a capacidade de discernimento à medida em que conseguirem distinguir situações, estabelecer relações entre os fatos passados e presentes, estabelecer hierarquias e valores. A criança tem capacidade de deixar seu mundo de referência e se colocar em outras paisagens culturais interessantes, em outro modo de vida: «a experiência da pluralidade modifica a visão de mundo, permitindo-lhe refutar seu ponto de vista pelos outros ». (MARZLOFF, 2013, p. 361).

Ler textos de patrimônio é entender como viviam os homens e quais valores existiam nas culturas que antecederam a cultura de que hoje fazemos parte; é entender que o desequilíbrio ambiental provocou mudança na forma como entendemos a caça atualmente no Brasil; nada está solto no fio da História. Pais conscientes sobre o perigo das armas fazem campanhas contra o uso destes brinquedos, enquanto na época de Lobato era normal uma criança ganhar uma espingardinha de chumbo que servia para realmente matar. As palavras ganham significados e sentidos no contexto ideológico no qual estão sendo usadas no fluxo contínuo do vir-a-ser do homem. Para Faraco (2019, p. 51),

[...] agimos, fazemos, produzimos e, ao mesmo tempo, recobrimos nosso fazer e seus produtos com uma densa trama de valores, imagens e discursos. Costuma-se dizer que a cultura tem uma face material e outra imaterial. Os dois adjetivos nos ajudam a ordenar a multiplicidade constitutiva de todo um modo de vida. No entanto, pode-se dizer que a face imaterial tem também sua materialidade, pois ela é feita de signos.

O que há na história da literatura infantil brasileira são muitos modos de vida, são muitas culturas expressas na materialidade dos signos. Não só os valores nascem e morrem, também as palavras nascem e morrem no movimento permanente entre os nossos fazeres e nossas linguagens no contexto de nossa cultura. 
Creio não ser apenas os valores éticos e morais que explicam a pouca utilização das obras de Lobato nas escolas, pois em algumas circunstâncias encontramos obras resumidas ou reescritas de forma higienizada. Há também outro fator: algumas palavras usadas na época da criação das obras não trazem nenhuma correspondência com as palavras que as crianças conhecem hoje; os alunos não encontram sentidos nelas.

A linguagem mostra seu movimento quando comparada com a forma de registro dos autores do século XXI. Segundo Eco (2002), a cada 200 anos seria necessário reescrever obras na mesma língua do original, para não correr o risco de perda total de compreensão. Alguns professores formados nas duas primeiras décadas do século XXI podem não ter lido, quando crianças, as obras de Lobato, e por isso não retomam estes textos de patrimônio porque nunca os tiveram em mãos; outros, por suspeitarem que o universo rural no qual a obra se situa não despertaria a atenção da criança; este universo está muito longe das brincadeiras com os games. Outros diriam que o texto tem muitas palavras de difícil compreensão para a idade dos pequenos.

Mais alguns trechos pinçados de Caçadas de Pedrinho ajudariam a mostrar que Eco pode ter razão:

Dos moradores do sítio de Dona Benta o mais andejo era o Marquês de Rabicó.

[...] Certo dia em que Rabicó se aventurou nesse mato em procura de orelhas-de-pau que crescem nos troncos podres, parece que as coisas não lhe correram muito bem, pois voltou na volada.

O segundo convidado foi o Visconde de Sabugosa, o qual aceitou a proposta com aquela dignidade e nobreza que marcavam todos os seus atos de fidalgos dos legítimos. Iria para vencer ou morrer. Viscondes da sua marca mostram o que valem justamente nos momentos perigosos.

- Avante, Saboia!

- Espera que te curo - disse Pedrinho, lembrando-se que trazia no bolso um pouco da pólvora dos pistões (LOBATO, 2019, p. 7-12). (Grifos meus).

Como pode ser constatado nas referências deste artigo, os trechos citados nestas páginas são parte da obra reeditada nesse ano de $2019 \mathrm{e}$, portanto, cumprem a norma da revisão ortográfica. Essa limpeza de acentos ou formas de grafar as palavras não interferem nos sentidos que o texto ganha quando está em frente aos olhos do pequeno leitor. Posso dizer que em minha região as palavras andejo, marquês, volada, visconde e nobreza já morreram. No entanto, na fricção com outras palavras é possível dar a elas 
um significado próximo ao de que precisaria o leitor para compreender o texto. As palavras no seu conjunto acionam saberes que ajudam a reconstruir o dito.

Igualmente já morreram as expressões fidalgos dos legítimos, viscondes da sua marca, Avante, Saboia!, Espera que te curo, pólvora dos pistões. Para entendê-las é preciso mais do que buscar apoio das outras palavras que as acompanham. É necessário o contexto histórico-cultural da época, e às vezes buscar um conhecimento específico de uma determinada área, como no caso da expressão Avante, Saboia!

Podem os professores oferecer uma obra que precisa de resgate cultural para que tudo seja entendido? É realmente preciso que tudo seja entendido? Será que toda criança faria opção por matar a onça, mesmo vivendo num mundo contemporâneo que não incentiva essa prática?

É certo que colocar notas de rodapés e explicações preliminares nas apresentações dos livros podem conduzir o leitor a uma interpretação desejada, esperada e reconhecida como adequada pela comunidade escolar. Por outro lado, um glossário no início de cada livro poderia ajudar a entender com maior eficiência o mapa decifratório da leitura. Não me refiro a um glossário padrão, um verbete de dicionário, mas a algo mais discursivo, que revelasse a cultura que banha tal ou qual expressão. Para deixar mais claro ao leitor faço um pequeno ensaio:

Espera que te curo: na época de Lobato, criança quando fazia arte muito grave poderia apanhar com chinelo, com o cinto do pai, com o relho do cavalo ou com uma varinha de marmelo. E como apanhavam! Bastava desobedecer duas vezes e na terceira era fatal. Toda vez que os pais ou responsáveis diziam: "Espera que te curo" as crianças já se aquietavam porque sabiam que a sova, a surra, serviria para curar a doença das arteirices das crianças.

Se as informações visuais que estão no texto e as que estão na mente do leitor, isto é, as que compõem a massa aperceptiva, assim nomeada por Jakubinskij (2012), são importantes para o ato de ler, nada mais justo que preparar as crianças para se situarem mais ou menos no contexto cultural e histórico, para que o diálogo entre leitor e escritor prospere mediado pelo texto.

Ao se considerar a natureza da linguagem em constante transformação, a função da linguagem em transmitir culturas e o tripé da leitura - texto, leitor e autor -, talvez a saída para esse problema seja encontrada na própria obra lobatiana: 
Com frequência valia-se do recurso de dar a D. Benta a função de contadora de histórias. É ela quem muitas vezes se incumbe de traduzir, para os demais habitantes do Sítio, textos que de outra maneira seriam de difícil acesso. É o caso de suas adaptações de obras universalmente conhecidas. Também nas obras originais muitas vezes D. Benta usa uma palavra mais erudita, apenas para depois explicá-la de forma coloquial. Essa simplificação na linguagem significa para Lobato a busca de clareza, do entendimento o mais direto possível. Jamais um empobrecimento, como é fácil constatar lendo qualquer de seus livros (SANDRONI, 1997, p. 57).

O papel do outro é essencial no cruzamento entre culturas, na apropriação de modos de vida que já não existem mais; apenas suas refrações são percebidas por poucos. O glossário e a limpeza ortográfica podem ajudar a recolocar em cenário obras escritas em outra época, mas será nas relações humanas, na dialogicidade entre professores e alunos que a interlocução entre culturas passadas e atuais se dará. Reproduzo aqui trechos de uma carta de 7/4/1946 de Lobato, publicada em Lopes e Gouvêia (apudLOPES, 1999, p. 51), dando conselhos a Hernani Ferreira, sobre leitura:

Quantos livros a recomendar... Que coisa difícil! Para cada temperamento, para cada personalidade que somos, tais os livros. [...] é preciso que você passeie pelo pensamento escrito dos grandes homens, das grandes inteligências, não para acumular como um museu o que eles dizem, mas para ir assimilando umas essências afins e construtoras do teu ego mental.

Assim como Lobato, acredito que é pela diversidade de estilos, de temas e de autores que os pequenos leitores farão suas escolhas e entrarão para a comunidade da cultura literária. Não é apenas o conteúdo do texto literário que será emancipador ou libertador, mas também a maneira como a pessoa aprende a se relacionar com o texto. Para Marzloff (2013, p. 306),

O conceito de emancipação tem o corolário oposto ao da alienação e se entende a emancipação como uma meta educacional que faz parte de um processo dinâmico de recomposição permanente de valores, de acordo com as mudanças na sociedade: os valores defendidos hoje não são mais os mesmos defendidos pelas gerações anteriores e valores defendidos em um determinado ponto do mundo não são compartilhados universalmente. Se, por outro lado, define-se a formação como o conjunto de dispositivos implementados para realizar um projeto global de educação, o ensino - que é a 
parte da formação apoiada pela instituição educacional - é concebido de tal maneira que torne possível o ideal de autonomia cidadã. Devemos, então, questionar as condições que possibilitam essa emancipação, levando em conta que esse ideal de formação, herdada do Iluminismo, está hoje em crise, pois promove, paralelamente, a ideia de que a educação consiste em acompanhar o indivíduo no reconhecimento do que ele é desde o início, e não em transformá-lo (MARZLOFF, 2013, p. 306). (Tradução minha).

A obra literária é por princípio uma obra aberta, nem tudo ali está dito, é nas relações entre autor, livro, leitor e leitores - todos num grande diálogo literário - que estes poderão aos poucos e permanentemente construir seus egos.

\section{Conclusão}

Como tantos outros brasileiros li as obras de Monteiro lobato, li as Caçadas de Pedrinho, escutei as histórias que meu pai contava de suas próprias caçadas, cuidei de seus passarinhos presos em gaiolas e não me tornei caçadora, pelo contrário, vejo com muita tristeza passarinhos presos.

As narrativas tradicionais clássicas, europeias e regionais, ajudam-nos a entender um pouco mais a história dos homens, a nossa própria história. Se a forma de escrever de Lobato já não corresponde mais à linguagem usada em 2019, se os valores culturais são outros, cabe a nós professores promover esse encontro entre culturas, que será sempre contraditório, heterogêneo, plural e em constante devir, mas também emancipador.

O homem do século XXI se constitui homem no fio da História; os textos de patrimônio são um acervo material que constitui referências culturais comuns a todos nós, porque não somos desvinculados do fluxo contínuo da história. Conhecer essas obras é importante para conhecermos a nós mesmos.

\section{REFERÊNCIAS}

ECO, H. A busca da língua perfeita na cultura européia. Trad. Antonio Angonese. Bauru: Edusc, 2002. FARACO, C. A. História do português. São Paulo: Parábola, 2019.

JAKUBINSKIJ, Lev. Sur la parole dialogale. In: JAKUBINSKIJ, Lev. Lev Jakubinskij, une linguistique de la parole (URSS, années 1920-1930). Textes édités et présentés par Irina Ivanova, traductions d'Irina Ivanova et Patrick Sériot. Limoges: Lambert Lucas, 2012. 
LOBATO, M. Caçadas de Pedrinho. Barueri: Ciranda Cultural, 2019.

LOPES, E. M. T. (Org.). Lendo e escrevendo Lobato. Belo Horizonte: Autêntica, 1999.

MARZLOFF, M. Lire 3 contes de Perrault: Le petit Poucet, Cendrillon, Le chat botté. Paris: Retz, 2009.

MARZLOFF, M. Litterature de jeunesse comme element d'emancipation dans la formation de l'enfant. Ensino Em Re-Vista, v. 20, n. 2, p. 305-314, jul./dez. 2013.

MORICEAU, J. M. Le fléau du Petit Chaperon rouge. Revue Historia, Paris, n. 805, Janvier 2014. SANDRONI, L. De Lobato a Bojunga: as reinações renovadas. Rio de Janeiro: Agir, 1987.

\section{SOBRe A AUTORA}

Adriana Pastorello Buim Arena é graduada em Filosofia e Pedagogia, tem Mestrado e Doutorado em Educação pela Universidade Estadual Paulista "Júlio de Mesquita Filho" - UNESP - Campus de Marília. É pesquisadora da Universidade Federal de Uberlândia - UFU - MG. Tem experiência na área de ensino e aprendizagem da língua materna na educação básica, com pesquisa atual sobre Pedagogia Freinet.

E-mail: dricapastorello@gmail.com.

Recebido em 02 de agosto de 2019 e aprovado em 25 de novembro de 2019. 